\title{
Factors Influencing Family Physician Adoption of Electronic Health Records (EHRs)
}

\author{
Imam M. Xierali, PhD, Robert L. Phillips, Jr., MD, MSPH, Larry A. Green, MD, \\ Andrew W. Bazemore, MD, MPH, and James C. Puffer, MD
}

Background: Physician and practice characteristics associated with family physician adoption of electronic health records (EHRs) remain largely unexplored but may be important for tailoring policies and interventions.

Methods: This was a cross-sectional study of EHR adoption using American Board of Family Medicine certification census data (2006-2011) for over 41,000 family physicians to test associations between demographic, geographic, and practice characteristics and EHR adoption.

Results: EHR adoption rates for family physicians grew from 37\% in 2006 to $68 \%$ in 2011 . No significant association was found with rural status (odds ration [OR], 0.985; 95\% confidence interval [CI], 0.932-1.042). Practicing in a medically underserved location (OR, 0.868; 95\% CI, 0.822-0.917) or geographic health professional shortage areas $(\mathrm{OR}, 0.904 ; 95 \% \mathrm{CI}, 0.831-0.984)$, or being an international medical graduate $(0 R, 0.769 ; 95 \%$ CI, $0.748-0.846)$ were negatively associated with adoption. Compared with physicians in group practices, physicians in solo practices (OR, 0.465; 95\% CI, 0.439$0.493)$ and small practices $(0 R, 0.769 ; 95 \%$ CI, 0.720-0.820) were less likely to adopt EHRs, whereas those in health maintenance organizations $(0 R, 5.482 ; 95 \%$ CI, 4.657-6.454) or with faculty status (OR, 1.527; 95\% CI, 1.386-1.684) were more likely.

Conclusions: Variation in EHR adoption is associated with physician and practice characteristics that may help guide intervention. These findings may be important to other specialties and could instruct interventions to improve adoption. Certification boards could play an important role in tracking EHR adoption and help target resources and facilitation. (J Am Board Fam Med 2013;26:388-393.)

Keywords: Electronic Health Record, Family Physician, Medically Underserved Area, Solo Practice

The use of electronic health records (EHRs) among physicians has increased rapidly in recent years. ${ }^{1,2}$

This article was externally peer reviewed.

Submitted 30 December 2012; revised 28 February 2013; accepted 6 March 2013.

From The Association of American Medical Colleges, Washington, DC (IMX); The American Board of Family Medicine, Lexington KY (RLP, JCP); Department of Family Medicine, University of Colorado Denver, Denver (LAG); and The Robert Graham Center for Policy Studies in Family Medicine and Primary Care, Washington, DC (AWB).

Funding: Support was provided by the American Board of Family Medicine, which contracts annually for health policy/health services research conducted by The Robert Graham Center for studies related to Maintenance of Certification and quality.

Disclaimer: The views and opinions stated in the paper are the sole responsibility of the authors and do not necessarily reflect the views or policy of the American Academy of Family Physicians.

Conflict of interest: none declared.

Corresponding author: Imam M. Xierali, PhD, The Association of American Medical Colleges, $2450 \mathrm{~N}$ Street NW, Washington, DC 20037 (E-mail: IXierali@aamc.org).
This growth coincides with federal efforts under the 2009 Health Information Technology for Economic and Clinical Health (HITECH) Act and despite mixed findings about their relative value. ${ }^{3,4}$ The Centers for Medicare \& Medicaid Services (CMS) also dramatically expanded incentives for adoption and "meaningful use" of EHRs. ${ }^{5}$ These incentives include penalties against practices that are not meaningfully using EHRs beginning in $2015 .^{6}$

Despite the rapid rise of the adoption of EHRs, several studies point to significant variation in EHR adoption that may persist or be difficult to overcome. A study of EHR adoption among family physicians in Florida found that it was significantly related to large practice size, urban location, and young physician age after controlling for other confounders. ${ }^{7}$ A multispecialty follow-up study of EHR adoption in Florida identified lower adoption rates among solo practices, single specialty practices, and older physicians. ${ }^{8} \mathrm{~A}$ 
similar study in Washington State found no rural/ urban variation, but adoption was higher in larger practices and much lower in solo practices; cost was identified as the main barrier. ${ }^{9}$ A recent study found that international medical graduates (IMGs) were significantly less likely to have a comprehensive EHR in their practices. ${ }^{10}$ These studies are informative in terms of identifying physician and practice characteristics predictive of struggling with EHR adoption. However, most predate the recent efforts of the HITECH and are state-specific, making it difficult to know whether they are generalizable or currently relevant. A recent National Center for Health Statistics study found that although trends in adoption of EHRs across geographic regions seemed to be converging, adoption continued to lag for non-primary care specialists, older physicians, and physicians in small and physician-owned practices. ${ }^{11}$

This study sought to identify characteristics of family physicians and their practices that are associated with lower EHR adoption rates. The purpose was to identify key barriers to EHR adoption by family physicians. Because family physicians are the physician specialty most widely distributed across geography and practice type, this study is likely to have general value to the effort to increase the adoption of EHRs. ${ }^{12}$ This study also explores the value of certifying board data for tracking trends in practice change and identifying physicians, practices, and their characteristics that are associated with the uptake of important practice innovations.

We hypothesized that EHR adoption varies significantly among physician and practice characteristics. Specifically, we hypothesized that female physicians and older physicians would have lower adoption rates, perhaps because of a greater likelihood of part-time work among both groups and for the latter a reluctance to make investments close to retirement. We hypothesized that IMGs would have a lower likelihood of EHR adoption than non-IMGs in general, perhaps because the majority of IMGs are from developing countries where EHR implementation tends be low. We also hypothesized that physicians practicing in underserved areas such as rural, geographic primary care health professional shortage areas, and medically underserved areas/populations would have lower adoptions rates because of fewer resources and less capacity to adopt EHRs.

\section{Methods}

The American Board of Family Medicine (ABFM) began transitioning all diplomates into the Maintenance of Certification (MOC) for Family Physicians in 2003. As part of the online application for the MOC examination, the ABFM requires that candidates complete a survey that includes demographic questions about the candidate and their practice. In December 2005, the ABFM added a question regarding EHR adoption to its pre-examination questionnaire, specifically asking all candidates, "Do you use an electronic medical record system in your office?" Using this data, we studied adoption rates among all new and recertifying family physicians from the years 2006 to 2011 ( $\mathrm{n}=8192,9430,9597,9475,2412$, and 2339 , respectively; a total 41,445 of physicians). The 2010 and 2011 ABFM sample sizes were smaller because $76 \%$ of family physicians who certified or recertified in 2003 and 2004 successfully earned a full 10 -year certification, allowing them to forego taking the examination for 3 years beyond which it would have been normally required. ${ }^{13,14}$ We obtained the IMG status of ABFM diplomats by matching them to the American Medical Association's Physician Masterfile. Multivariable logistic regression then was used to assess the association of physician demographic and practice characteristics with EHR adoption across the study years. The factors considered include physician age and sex, practice location, IMG status, and practice setting (for example, solo or group practice). We restricted the data sample to the 50 United States and District of Columbia.

\section{Results}

Statistically significant but practically small sample differences were observed across age, sex, and medical degree (MD vs. DO) (see Table 1). There were $6 \%$ to $9 \%$ increases in the representation of IMGs in the 2010 and 2011 cohorts. The practice categories remained relatively stable over the study years. However, small increases in the representation of solo practices (3\% to $5 \%$ of the overall percentage) were observed for 2010 and 2011, whereas a small drop was observed for educators $(<2 \%)$, group practitioners $(1 \%$ to $3 \%)$, and partnerships $(<2 \%)$. We observed no significant differences between the cohorts across geographic distribution in terms of underserved areas and census regions.

EHR adoption rates among family physicians rose significantly from a national rate of $37 \%$ in 
Table 1. Demographic Characteristics of Surveyed American Board of Family Medicine (ABFM) Candidates

\begin{tabular}{|c|c|c|c|c|c|c|c|}
\hline Variable & $\begin{array}{c}2006 \\
(\mathrm{n}=8192)\end{array}$ & $\begin{array}{c}2007 \\
(\mathrm{n}=9430)\end{array}$ & $\begin{array}{c}2008 \\
(\mathrm{n}=9597)\end{array}$ & $\begin{array}{c}2009 \\
(\mathrm{n}=9475)\end{array}$ & $\begin{array}{c}2010 \\
(\mathrm{n}=2412)\end{array}$ & $\begin{array}{c}2011 \\
(\mathrm{n}=2339)\end{array}$ & $\begin{array}{c}\text { Overall } \\
(\mathrm{n}=41,445)\end{array}$ \\
\hline Male sex* & 68.1 & 66.9 & 66.8 & 65.2 & 67.5 & 67.9 & 66.8 \\
\hline Age* (mean) $^{*}$ & 47.5 & 47.9 & 48.6 & 49.5 & 51.3 & 51.3 & 48.7 \\
\hline$<40$ & 22.6 & 22.0 & 19.4 & 16.5 & 8.9 & 9.4 & 18.8 \\
\hline $40-60$ & 69.5 & 68.6 & 69.5 & 70.2 & 74.2 & 73.2 & 70.2 \\
\hline$\geq 60$ & 7.9 & 9.4 & 11.1 & 13.3 & 16.9 & 17.2 & 10.6 \\
\hline MD degree* & 92.8 & 92.6 & 92.2 & 92.1 & 90.1 & 90.0 & 92.2 \\
\hline International medical graduate* & 10.4 & 11.9 & 13.2 & 15.2 & 22.6 & 20.6 & 13.8 \\
\hline \multicolumn{8}{|l|}{ Type of organization* } \\
\hline Administration & 1.1 & 1.1 & 1.2 & 1.1 & 1.2 & 1.5 & 1.1 \\
\hline Educator & 5.3 & 5.2 & 4.7 & 4.8 & 3.5 & 3.0 & 4.8 \\
\hline Government & 5.8 & 6.3 & 6.9 & 6.7 & 7.3 & 6.9 & 6.6 \\
\hline Group & 43.5 & 43.7 & 44.1 & 43.3 & 39.5 & 41.9 & 43.3 \\
\hline HMO & 3.4 & 3.3 & 3.1 & 3.0 & 2.6 & 2.4 & 3.1 \\
\hline Independent (solo) & 18.8 & 18.9 & 19.3 & 20.1 & 25.5 & 23.0 & 19.9 \\
\hline Partnership & 13.2 & 12.7 & 11.7 & 11.3 & 10.3 & 10.2 & 12.0 \\
\hline Others & 8.9 & 8.7 & 9.2 & 9.7 & 10.0 & 11.0 & 9.3 \\
\hline Rural $^{\dagger}$ & 19.6 & 18.4 & 18.9 & 18.4 & 16.2 & 16.9 & 18.5 \\
\hline Geographic HPSAs & 7.0 & 6.7 & 6.9 & 7.2 & 7.4 & 7.1 & 7.0 \\
\hline MUA/P & 22.3 & 21.0 & 21.2 & 21.6 & 21.6 & 22.7 & 21.6 \\
\hline \multicolumn{8}{|l|}{ Census region* } \\
\hline Northeast & 14.8 & 14.9 & 14.5 & 14.6 & 15.9 & 15.1 & 14.8 \\
\hline Midwest & 27.2 & 26.8 & 26.6 & 25.9 & 25.5 & 25.9 & 26.5 \\
\hline South & 33.6 & 33.5 & 34.5 & 34.2 & 35.7 & 37.1 & 34.2 \\
\hline West & 24.3 & 24.8 & 24.4 & 25.4 & 22.8 & 21.9 & 24.5 \\
\hline
\end{tabular}

Values are shown as percentages.

${ }^{*} P<.0001$.

${ }^{\dagger} P<.01$.

HMO, health maintenance organization; HPSA, health professional shortage area; MUA/P, medically underserved area/population.

2006 to $68 \%$ in 2011 ( $P$ for trend $<.0001$ ). However, the growth rate of EHR adoption varied significantly across demographic, geographic, and practice characteristics (see Table 2). We found no significant differences in EHR adoption among family physicians of allopathic versus osteopathic education. Younger family physicians were much more likely to adopt EHRs than older family physicians (odds ratio [OR], 0.980; 95\% confidence interval [CI], 0.977-0.982). Female family physicians were less likely to have adopted EHRs (OR, 0.896; 95\% CI, 0.857-0.938), as were IMGs (OR, 0.796; 95\% CI, 0.748-0.846). EHR adoption varied significantly along practice settings. Compared with family physicians in group practice, family physicians in health maintenance organizations (OR, 5.482; 95\% CI, 4.657-6.454), government (OR, 1.762; 1.615-1.923), and faculty settings (OR, 1.527 ; $95 \%$ CI, $1.386-1.684)$ were more likely to adopt EHRs, whereas physicians in solo practices
(OR, 0.465; 95\% CI, 0.439-0.493), small partnerships (OR, 0.769; 95\% CI, 0.720-0.820), administration (OR, 0.478; 95\% CI, 0.391-0.584), and other settings (OR, 0.621; 95\% CI, 0.577-0.668) were less likely to do so. Although rural physicians seemed to be slightly behind their urban peers in EHR adoption, this lag was not significant (OR, 0.985; 95\% CI, 0.932-1.042). Physicians practicing in a geographic health professional shortage area (OR, 0.904; 95\% CI, 0.831-0.984) or medically underserved area/population (OR, 0.868; 95\% CI, $0.822-0.917$ ) were in general less likely to adopt an EHR. There were also significant regional differences: family physicians in the West were more likely to adopt EHR compared with those in the Northeast (Table 3).

\section{Discussion}

Using a new data source that provides a census of certifying and recertifying family physicians, we 
Table 2. EHR Adoption Rate By Physician/Practice Characteristics

\begin{tabular}{|c|c|c|c|c|c|c|c|}
\hline Variable & 2006 & 2007 & 2008 & 2009 & 2010 & 2011 & Difference* \\
\hline National rate & 36.9 & 42.9 & 49.1 & 54.3 & 57.4 & 68.0 & 31.1 \\
\hline Male sex & 37.5 & 42.4 & 49.6 & 53.8 & 55.1 & 66.5 & 29.0 \\
\hline \multicolumn{8}{|l|}{ Age, years } \\
\hline$<40$ & 41.6 & 48.7 & 55.7 & 61.8 & 63.3 & 75.5 & 33.9 \\
\hline $40-60$ & 36.4 & 42.2 & 48.4 & 54.8 & 59.1 & 69.5 & 33.1 \\
\hline$\geq 60$ & 28.3 & 35.2 & 41.7 & 42.4 & 46.9 & 57.3 & 29.0 \\
\hline MD degree & 37.1 & 43.0 & 49.1 & 54.6 & 57.5 & 68.1 & 31.0 \\
\hline International medical graduate & 29.6 & 35.9 & 41.8 & 46.7 & 50.0 & 58.3 & 28.7 \\
\hline \multicolumn{8}{|l|}{ Type of organization } \\
\hline Administration & 19.3 & 23.8 & 40.5 & 38.0 & 43.3 & 50.0 & 30.7 \\
\hline Educator & 48.3 & 55.3 & 62.4 & 69.8 & 69.4 & 81.7 & 33.4 \\
\hline Government & 56.9 & 60.9 & 62.8 & 69.5 & 76.1 & 82.0 & 25.1 \\
\hline Group & 37.3 & 45.7 & 53.1 & 59.4 & 64.8 & 74.3 & 37.0 \\
\hline HMO & 73.1 & 84.4 & 90.2 & 92.0 & 90.3 & 94.6 & 21.5 \\
\hline Independent (solo) & 25.7 & 28.4 & 32.3 & 35.1 & 39.9 & 49.9 & 24.2 \\
\hline Partnership & 35.4 & 37.6 & 46.0 & 53.4 & 56.5 & 71.1 & 35.7 \\
\hline Others & 29.6 & 34.6 & 39.4 & 44.2 & 48.8 & 62.8 & 33.2 \\
\hline Rural & 32.9 & 40.1 & 46.1 & 50.5 & 58.7 & 68.2 & 35.3 \\
\hline Geographic HPSAs & 35.0 & 36.8 & 42.2 & 49.8 & 53.4 & 71.3 & 36.3 \\
\hline MUA/Ps & 33.2 & 39.5 & 43.7 & 49.1 & 55.7 & 68.2 & 35.0 \\
\hline \multicolumn{8}{|l|}{ Census regions } \\
\hline Northeast & 34.1 & 39.3 & 46.7 & 50.1 & 58.7 & 65.9 & 31.8 \\
\hline Midwest & 36.4 & 42.0 & 49.3 & 53.9 & 53.2 & 67.8 & 31.4 \\
\hline South & 34.0 & 40.1 & 45.9 & 51.7 & 57.3 & 67.7 & 33.7 \\
\hline West & 43.3 & 49.9 & 54.8 & 60.7 & 61.2 & 70.0 & 26.7 \\
\hline
\end{tabular}

Values are shown as percentages.

*The differences in adoption rates are between 2006 and 2011. All $P<.0001$ for trend.

EHR, electronic health records; HMO, health maintenance organization; HPSA, health professional shortage area; MUA/P, medically underserved area/population.

found that family physicians' adoption of EHRs rose significantly. New and recertifying family physicians participating in MOC (about $85 \%$ of all family physicians and general practitioners in the United States) ${ }^{15}$ regardless of their age, sex, practice setting, rural or urban locations, or location in or out of medically underserved areas, increasingly adopted EHRs between 2006 and 2011, reaching 68\% nationally by 2011. Despite this broad trend, potentially important differences are noted, particularly by practice characteristics and geographic location. While these differences have plausible explanations that may benefit from more robust explorations, they also suggest opportunities for facilitation and support to help those lagging behind. Compared with hospitals and large practices, for instance, family physicians in solo and small practices lack the capital needed for EHR adoption and lack access to information technology staff to assist with EHR installation and maintenance. Small and solo practices still comprise $32 \%$ of family physicians (see Table 1), and this is unlikely to change for many communities, including most of rural America. The EHR incentive programs may be able to overcome the financial barriers but may not surmount the technical support problems these practices face.

This study may have direct implications for the regional extension centers (RECs). As the federally funded extension program to support and serve health care providers, RECs may need to reassess their focus on developing solutions for physicians more likely to lag behind in EHR adoption. These physicians may need specific solutions to help them adopt and meaningfully use EHRs. RECs could enhance their efforts by providing training and support services to assist those in solo and small practices in adopting EHRs, offering information and guidance to help with EHR implementation and developing technical assistance solutions that these practices do not currently have. Regional variation in EHR adoption suggests that solutions for lagging adopters may need to differ by region. 
Table 3. Logistic Regression Odds Ratios of the Predictors of EHR Adoption (2006-2011)

\begin{tabular}{|c|c|c|c|c|}
\hline Variable & Estimate & $P$ & OR & $95 \% \mathrm{CI}$ \\
\hline Intercept & 0.6055 & $<.0001$ & & \\
\hline \multicolumn{5}{|l|}{ Exam year (reference: 2006) } \\
\hline 2007 & 0.2686 & $<.0001$ & 1.308 & $1.228-1.394$ \\
\hline 2008 & 0.5634 & $<.0001$ & 1.757 & $1.649-1.871$ \\
\hline 2009 & 0.8191 & $<.0001$ & 2.269 & $2.129-2.417$ \\
\hline 2010 & 1.0624 & $<.0001$ & 2.893 & $2.625-3.190$ \\
\hline 2011 & 1.5325 & $<.0001$ & 4.630 & $4.177-5.131$ \\
\hline Age* & -0.0207 & $<.0001$ & 0.980 & $0.977-0.982$ \\
\hline Female (reference: male) & -0.1097 & $<.0001$ & 0.896 & $0.857-0.938$ \\
\hline IMG (reference: non-IMG) & -0.2286 & $<.0001$ & 0.796 & $0.748-0.846$ \\
\hline Type of organization & . & . & . & - \\
\hline Administration & -0.7386 & $<.0001$ & 0.478 & $0.391-0.584$ \\
\hline Educator & 0.4236 & $<.0001$ & 1.527 & $1.386-1.684$ \\
\hline Government & 0.5666 & $<.0001$ & 1.762 & $1.615-1.923$ \\
\hline \multicolumn{5}{|l|}{ Group (reference) } \\
\hline $\mathrm{HMO}$ & 1.7015 & $<.0001$ & 5.482 & $4.657-6.454$ \\
\hline Independent (solo) & -0.7655 & $<.0001$ & 0.465 & $0.439-0.493$ \\
\hline Partnership & -0.2633 & $<.0001$ & 0.769 & $0.720-0.820$ \\
\hline Others & -0.4771 & $<.0001$ & 0.621 & $0.577-0.668$ \\
\hline Rural (reference: urban) & -0.0147 & .6061 & 0.985 & $0.932-1.042$ \\
\hline Geographic-HPSAs (reference: non-Geographic HPSA) & -0.1010 & .0191 & 0.904 & $0.831-0.984$ \\
\hline MUA/P (reference: non-MUAP) & -0.1413 & $<.0001$ & 0.868 & $0.822-0.917$ \\
\hline \multicolumn{5}{|l|}{ Census region } \\
\hline Northeast (reference) & - & - & - & - \\
\hline Midwest & -0.0168 & .6186 & 0.983 & $0.920-1.051$ \\
\hline South & -0.0134 & .6848 & 0.987 & $0.925-1.053$ \\
\hline West & 0.1866 & $<.0001$ & 1.205 & $1.126-1.290$ \\
\hline
\end{tabular}

Of the 41,445 total, 606 cases were excluded because of missing values in the independent variables.

*Age is treated as a continuous variable in the regression. Correct prediction is $67.5 \%$ with a 0.500 cut off $\left(R^{2}=0.0927\right.$; maximum rescaled $R^{2}=$ 0.1236; $P=.1722$, Hosmer and Lemeshow goodness-of-fit test). EHR, electronic health records; HMO, health maintenance organization; HPSA, health professional shortage area; IMG, international medical graduates, MUA/P, medically underserved area/population.

This study also suggests that other certifying boards could have a role in monitoring this important practice objective and its outcomes. Certifying boards may also be potential partners with the CMS or RECs in identifying and working with specific practices that are unable or unwilling to surmount barriers to adoption. Some boards already work with the CMS to bridge quality reporting requirements for their diplomates, so a precedent exists as a bridge for other quality improvement priorities.

Certain limitations exist in this study. The ABFM data does not capture information for family physicians who are not seeking board certification but are still practicing medicine. The ABFM does have a large, stable, annual sample returning for their MOC, examination with a $100 \%$ response rate to the EHR question, and should remain a reliable resource for monitoring adoption and identifying characteristics associated with lower adoption. These findings are specific to family physicians and may not be generalizable to all specialties, but because of the broad geographic and practice setting distribution across the entire US population, they may have important lessons for policy makers and health services researchers. The 2010 and 2011 ABFM sample sizes were smaller than usual but still remained considerably large from a survey sampling perspective. This cohort had higher proportion of examinees retaking the test after a recent failed attempt because $76 \%$ of those certified in 2003 and 2004 earned a 10 -year certification. However, because of the significant negative association between the number of failed examination attempts and EHR adoption in general (data not shown), our estimate of EHR adoption may be more conservative for these later 2 years than it would have been the case without the implementation of a 10 -year pathway. 
The ABFM did not specifically define the term $E H R$ in its questionnaire. However, ABFM's EHR survey question has been consistent throughout the study period. Furthermore, family physicians and other outpatient physicians adopted electronic billing systems in the 1980s, and the rise of comprehensive EHRs has been a feature of medical practice for the last 2 decades, with various national policies and efforts focused on EHR adoption. This means that a general understanding of what an EHR entails is common among physicians nowadays. The ABFM captured whether candidates used an EHR, but it did not explore "meaningful use" or specific functions of EHRs. The ABFM data has yet to explore the role of EHR in the implementation of health information exchanges, which aim to provide better patient-centered health care while improving quality and reducing cost. ${ }^{16}$ Nevertheless, the study does get to the fundamental issue of EHR adoption and thus still bears important generalizable lessons for barriers to EHR adoption.

\section{Conclusions}

The majority of family physicians now have adopted EHRs regardless of sex, age, practice setting, and geography. However, older physicians, IMGs, those practicing in solo and small practices, and those practicing in medically underserved areas and caring for poorer populations represent key opportunities to accelerate EHR adoption and garner whatever benefits accompany it. The practices yet to adopt EHRs may benefit from proper assistance and support. There may also be partnership opportunities for certifying boards and federal agencies to continue monitoring and assist specific practices in overcoming barriers to EHR adoptions. While further monitoring of these trends is important, the more challenging issue will be the sufficiency of EHRs to help family physicians take better care of their patients.

The authors thank Drs. Carlos R. Jaén, Stephen M. Petterson, Jason C. Rinaldo, and Warren P. Newton for helpful comments on earlier drafts. This paper was completed for publication while Dr. Xierali was at the American Academy of Family Physicians. He is currently Manager for Public Health and Diversity Initiatives at the Association of American Medical Colleges.

\section{References}

1. Hsiao CJ, Hing E, Socey TC, Cai B. Electronic health record systems and intent to apply for meaningful use incentives among office-based physician practices: United States, 2001-2011. NCHS Data Brief 2011;(79):1-8.

2. Xierali IM, Hsiao CJ, Puffer JC, et al. The rise of electronic health record adoption among family physicians. Ann Fam Med 2013;11:14-9.

3. Blumenthal D. Launching HITECH. N Engl J Med 2010;362:382-5.

4. Jha AK. The promise of electronic records: around the corner or down the road? JAMA 2011;306:880-1.

5. Centers for Medicare \& Medicaid Services. EHR incentive programs. The official web-site for the Medicare and Medicaid electronic health record (EHR) incentive programs. Available from: http:// www.cms.gov/EHRIncentivePrograms/. Accessed May 26, 2011.

6. Blumenthal D. Stimulating the adoption of Health Information Technology. N Engl J Med 2009;360: 1477-9.

7. Menachemi N, Perkins RM, van Durme DJ, Brooks RG. Examining the adoption of electronic health records and personal digital assistants by family physicians in Florida. Inform Prim Care 2006;14:1-9.

8. Menachemi N, Powers TL, Brooks RG. Physician and practice characteristics associated with longitudinal increases in electronic health records adoption. J Healthc Manag 2011;56:183-97.

9. Stream GR. Trends in adoption of electronic health records by family physicians in Washington State. Inform Prim Care 2009;17:145-52.

10. Mazurenko O, Gupte G, Yeager VA. International medical graduates and health information technology use in the United States. Adv Health Care Manag 2012;12:121-40.

11. Decker SL, Jamoom EW, Sisk JE. Physicians in nonprimary care and small practices and those age 55 and older lag in adopting electronic health record systems. Health Aff (Millwood) 2012;31:1108-14.

12. Primary care workforce facts and stats no. 3. AHRQ Publication no. 12-P001-4-EF. January 2012. Rockville, MD: Agency for Health Care Policy and Research. Available from: http://www.ahrq.gov/research/pcwork3.htm. Accessed May 8, 2012.

13. Puffer JC, Bazemore AW, Newton WP, et al. Engagement of family physicians seven years into Maintenance of Certification. J Am Board Fam Med 2011;24:483-4.

14. Puffer JC, Bazemore AW, Jaén CR, et al. Engagement of family physicians in Maintenance of Certification remains high. J Am Board Fam Med 2012; 25:761-2.

15. Xierali IM, Rinaldo JC, Green LA, et al. Family physician participation in Maintenance of Certification. Ann Fam Med 2011;9:203-10.

16. Health information exchange (HIE). HealthIT.gov. Available from: http://www.healthit.gov/providersprofessionals/health-information-exchange-hie. Accessed February 20, 2013. 